\title{
BMJ Open Cumulative inflammatory burden and obesity as determinants of insulin resistance in patients with established rheumatoid arthritis: cross- sectional study
}

\author{
Sara Manrique-Arija, ${ }^{1}$ Natalia Mena-Vazquez (i) , ${ }^{1}$ Inmaculada Ureña, ${ }^{1}$ José Rioja, ${ }^{2}$ \\ Pedro Valdivielso, ${ }^{3}$ Leovigildo Ginel-Mendoza, ${ }^{4}$ Salomé Abad-Sánchez, ${ }^{4}$ \\ Francisco G Jiménez-Núñez, ${ }^{1}$ Begoña Oliver-Martos, ${ }^{5}$ \\ Antonio Fernandez-Nebro (i) ${ }^{1}$
}

To cite: Manrique-Arija S, Mena-Vazquez N, Ureña I, et al. Cumulative inflammatory burden and obesity as determinants of insulin resistance in patients with established rheumatoid arthritis: crosssectional study. BMJ Open 2021;11:e044749. doi:10.1136/ bmjopen-2020-044749

- Prepublication history and supplemental material for this paper is available online. To view these files, please visit the journal online (http://dx.doi org/10.1136/bmjopen-2020044749).

Received 14 September 2020 Revised 29 December 2020 Accepted 13 January 2021

Check for updates

(c) Author(s) (or their employer(s)) 2021. Re-use permitted under CC BY-NC. No commercial re-use. See rights and permissions. Published by BMJ.

For numbered affiliations see end of article.

\section{Correspondence to} Dr Natalia Mena-Vazquez; nataliamenavazquez@gmail. com

\section{ABSTRACT}

Objectives To describe the prevalence of insulin resistance $(\mathrm{IR})$ in patients with established rheumatoid arthritis (RA) and to analyse the contribution of cumulative inflammatory burden and other factors to its development. Design Observational cross-sectional study.

Participants Patients with RA and controls matched for age, sex and Body Mass Index. We excluded patients with diabetes.

Settings Patients from an RA inception cohort at Hospital Regional Universitario de Málaga, Spain, were recruited between September 2016 and May 2018.

Primary and secondary outcome measures IR was evaluated using the homeostasis model assessment for IR and beta-cell function and the quantitative insulin sensitivity check index. Other variables included the cumulative 28-Joint Disease Activity Score (DAS28) with $C$ reactive protein (CRP) body composition and cytokines Two logistic regression models were constructed to identify factors associated with IR in patients with RA. Results Eighty-nine patients with RA and 80 controls were included. The prevalence of IR was similar in both cases and controls. Inflammatory activity was controlled appropriately in patients during follow-up (mean DAS28 $3.1(0.8)$ ). The presence of IR in patients with RA was associated with obesity (OR 6.01, 95\% $\mathrm{Cl} 1.9$ to 8.7), higher cumulative DAS28-CRP values during follow-up (OR $2.8,95 \% \mathrm{Cl} 1.3$ to 6.0 ), and higher interleukin- $1 \beta$ levels (OR 1.6, 95\% $\mathrm{Cl} 1.1$ to 2.4). The second model showed that the risk of IR increased by $10 \%$ for each kilogram of excess body fat.

Conclusion In patients with well-controlled, established $\mathrm{RA}, \mathrm{IR}$ is associated mainly with poorer control of inflammation from diagnosis and with obesity, specifically total fat mass.

\section{INTRODUCTION}

Rheumatoid arthritis (RA) is a chronic inflammatory disease characterised by persistent synovitis, bone erosion and functional
Strengths and limitations of this study

- The control group in this study was matched with the cases not only by age and sex but also by Body Mass Index, not generally controlled for elsewhere.

- Widely validated questionnaires, indices and measurement parameters were used to minimise measurement biases.

- The cross-sectional evaluation of insulin resistance estimates the association between variables but does not guarantee causality of the event of interest.

disability. It is associated with premature death $^{1-3}$ and multiple morbidities, ${ }^{12}$ mainly because the cardiovascular risk of patients with RA is similar to that of patients with type 2 diabetes mellitus (DM). ${ }^{3}$ Accelerated atherosclerosis in patients with RA is due to the presence of traditional and nontraditional cardiovascular risk factors, including systemic inflammation, drugs and insulin resistance (IR). ${ }^{45}$

In the general population, IR has been confirmed as a risk factor for cardiovascular diseases, DM and metabolic syndrome. ${ }^{6}$ Its main determinant is obesity, although it has also been associated with older age, hypertension and a sedentary lifestyle. Abundant data suggest a connection between IR and chronic inflammation. ${ }^{7} 8$ Adipose tissue produces proinflammatory cytokines and adipokines, including tumour necrosis factor alpha $(\mathrm{TNF}-\alpha)$, which reduces sensitivity to insulin and contributes to endothelial dysfunction. ${ }^{9}$ The relationship between adipokines, proinflammatory cytokines and $\operatorname{IR}^{10}$ is unclear in $\mathrm{RA}$, although it could play a key role in the pathogenesis of accelerated atherosclerosis 
associated with chronic inflammatory states. Various studies have been specifically designed to investigate IR in RA. ${ }^{511-14}$ While most confirm an association between IR and inflammation, other factors continue to play a stronger role, such as abdominal obesity with sarcopenia, sedentary lifestyle and drugs. ${ }^{15}$

Almost all studies that examine the relationship between IR and RA were carried out in patients with chronic RA and numerous comorbid conditions associated with cardiovascular risk factors in case series not controlled for Body Mass Index (BMI). Furthermore, as these studies have a cross-sectional design, they only take into account values for inflammation recorded at a particular point in time. We previously studied a group of untreated patients with recent-onset RA and a control group matched for age, sex and BMI. The patients were followed up for 6 months. ${ }^{16}$ The results showed that IR was not present at diagnosis and did not appear after 6 months of treatment if the disease was well controlled. However, our results also showed that patients with higher fat mass and a longer diagnostic and therapeutic delay had the worst IR data. Based on these findings, the hypothesis of the present study was that IR in patients with RA, as with other determinants of disease, can be prevented in the long term with tight control of inflammation from onset.

The objectives of the present study were as follows: (1) to compare the prevalence of IR in an inception cohort of patients with RA and an equivalent group of healthy controls, and (2) to analyse the effect of IR on the cumulative inflammatory burden over at least 5 years, together with other possible factors that contribute to IR.

\section{METHODS}

We carried out an observational cross-sectional study of patients with RA. The study was performed at Instituto de Investigación Biomédica de Málaga by the Department of Rheumatology of Hospital Regional Universitario de Málaga (HRUM), Malaga, Spain.

\section{Patients}

We consecutively included patients from the RA inception cohort at HRUM. All patients had been diagnosed and treated during the first 12 months since the onset of their disease. The inclusion criteria were as follows: RA according to the 2010 classification criteria of the American College of Rheumatology/European League Against Rheumatism, ${ }^{17}$ diagnosis made between 2007 and 2011, age of $>16$ years, and prospective follow-up with at least two annual 28-Joint Disease Activity Score (DAS28) determinations. Patients were recruited between September 2016 and May 2018. We excluded patients with any inflammatory, rheumatic or autoimmune disease other than RA (except for secondary Sjögren syndrome), a diagnosis of DM or impaired glucose tolerance (American Diabetes Association 2010 criteria), ${ }^{18}$ active infection, pregnancy, current or previous treatment with oral antidiabetic agents or insulin, and new treatments or changes in dose during the 3 months preceding the date of inclusion.

The control group was made up of healthy controls selected from among those who attended a health centre in the same geographical area. All controls fulfilled all of the inclusion criteria and none of the exclusion criteria. The controls were matched with the cases for age, sex, race and BMI. According to BMI, each control was taken from the same group of the WHO classification for each patient with RA (normal range: $19.0-24.9 \mathrm{~kg} / \mathrm{m}^{2}$, overweight: $25.0-29.9 \mathrm{~kg} / \mathrm{m}^{2}$ and obesity: $\geq 30 \mathrm{~kg} / \mathrm{m}^{2}$ ).

\section{Patient and public involvement}

Neither patients nor the public contributed to the study design or performance, and participants were not involved in the publication of the results. The results of the study will be provided to patients on request, and the conclusions will be reported in publications and meetings.

\section{Protocol}

Cohort patients were followed up and treated according to a pre-established protocol and were managed with treat-to-target strategies following clinical practice guidelines for RA in Spain (GUIPCAR 2017).${ }^{19}$ All participants were interviewed and examined by a rheumatologist on the study index date. Samples were collected between 09:00 and 10:00 after 12-16 hours of fasting. In order to detect impaired glucose tolerance, subjects with baseline blood glucose levels $<126 \mathrm{mg} / \mathrm{dL}$ underwent an oral glucose tolerance test (OGTT).

\section{Variables and definitions}

The outcome measures were IR and insulin sensitivity. IR was estimated using the homeostasis model assessment for insulin resistance (HOMA-IR) ${ }^{11}$ and defined as a HOMA-IR score $>2.29$, based on the 90th percentile for healthy persons ${ }^{20}$ and using the homeostasis model assessment of $\beta$-cell function. ${ }^{11}$ Sensitivity to insulin was estimated using the quantitative insulin sensitivity check index (QUICKI), with a threshold value of 0.337 $(\mu \mathrm{U} \times \mathrm{mmol} / \mathrm{mL} \times \mathrm{L}){ }^{21}$

On the index date, we recorded epidemiological variables, comorbidities, traditional cardiovascular risk factors, diet, physical activity, anthropometric data and BMI.

Arterial hypertension was defined as an arterial pressure of $\geq 140 / 90 \mathrm{~mm} \mathrm{Hg}$ or current treatment with antihypertensive medication. ${ }^{22}$ Glucose and metabolic disorders and DM were diagnosed based on the recommendations of the American Diabetes Association 2010. ${ }^{23}$ Dyslipidaemia and metabolic syndrome were defined in accordance with the guidelines of the National Cholesterol Education Programme Adult Treatment Panel III. ${ }^{24}$ Levels of total cholesterol, triglycerides, high-density lipoprotein and low-density lipoprotein (LDL) were evaluated using enzymatic methods. ${ }^{25}$ Levels of oxidised anti-LDL and serum insulin were determined using enzyme-linked chemiluminescence assay. 
Physical activity was measured using the International Physical Activity Questionnaire, taking into account physical activity (low, $<600$ metabolic equivalents of task (METs); moderate, 600-1500 METs; and high >1500 METs). ${ }^{26}{ }^{27}$ Sedentary lifestyle was considered less than 600 METs.

Adherence to a Mediterranean diet was evaluated using a validated questionnaire. Adherence was defined as a score of $\geq 9$ out of $14 .^{28}$

Anthropometric data included BMI $\left(\mathrm{kg} / \mathrm{m}^{2}\right)$ and percentage of obese patients, ${ }^{29}$ waist circumference $(\mathrm{cm})$, hip circumference $(\mathrm{cm})$ and the Waist-Hip Index. ${ }^{30}$ Body composition was measured using dual-energy X-ray absorptiometry (DXA, GE Lunar Prodigy enCORE 2006) and included total mass $(\mathrm{kg})$, fat mass $(\mathrm{g})$, lean mass $(\mathrm{g})$, and lean mass and android and gynoid fat mass. The Fat Mass Index was defined as fat mass $(\mathrm{kg}) /$ height squared $\left(\mathrm{m}^{2}\right)$ and Fat-Free Mass Index as fat-free mass $(\mathrm{kg}) /$ height squared $\left(\mathrm{m}^{2}\right)$. The values of fat mass and fat-free mass were obtained using DXA. ${ }^{31}$

Clinical data comprised rheumatoid factor, which was positive if $>20 \mathrm{IU} / \mathrm{mL}$, and anticitrullinated protein antibody, which was positive if $>10 \mathrm{IU} / \mathrm{mL}$. Cumulative inflammatory burden was assessed using DAS28 score with $\mathrm{C}$ reactive protein (CRP) level (range 0-9.4) ${ }^{32}$ recorded at each visit throughout follow-up. High activity was defined as DAS28-CRP score of $>5.1$, moderate activity as 3.2-5.1, low activity as 2.6-3.2 and remission as $\leq 2.6$. We also took into account severity variables such as the presence of erosions and the mean Health Assessment Questionnaire score throughout the course of the disease. ${ }^{33}$ Treatment was with synthetic disease-modifying anti-inflammatory drugs (DMARDs) and biological DMARDs. The laboratory values measured in all patients were as follows: serum high-sensitivity CRP, TNF- $\alpha$, interleukin (IL)-6, IL-1 $\beta$, adiponectin, resistin, leptin, and insulin-like growth factor (IGF)-1. The laboratory kits used and their reference values are shown in the online supplemental material.

\section{Statistical analysis}

Variables are expressed as mean (SD), median (IQR) or number $(\%)$. Comparisons between groups were performed using the $\chi^{2}, t$ or Mann-Whitney test, depending on the normality of the distribution. Binary logistic regression analysis was performed (dependent variable: IR measured using HOMA-IR). Multicollinearity of independent variables was verified using the Pearson correlation coefficient $(r>0.4)$. Sample size was calculated assuming a prevalence of IR in RA of $51 \%$ and considering as relevant a $30 \%$ difference with respect to controls. With a two-sided $\alpha$ error of 0.05 and a $\beta$ error of 0.20 , the necessary sample size would be 77 participants per group. ${ }^{34}$ Sample size was increased by $10 \%$ to account for possible losses. The analysis was performed using $\mathrm{R}$ Commander V.2.3-0.

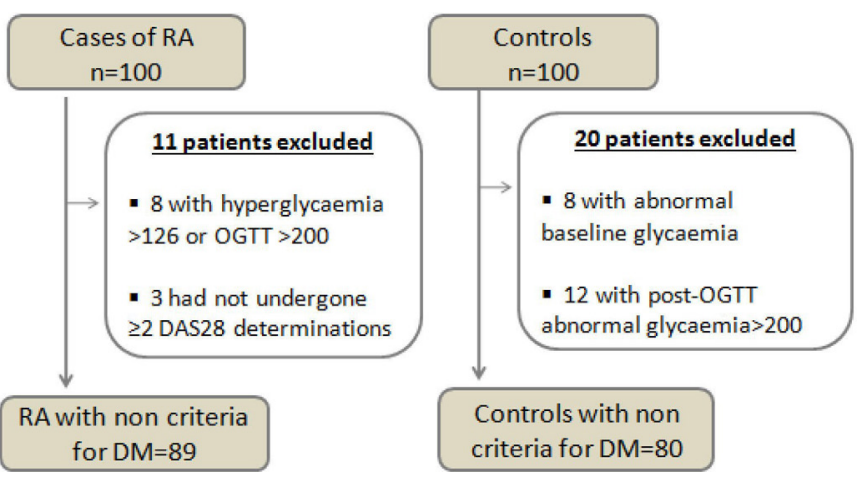

Figure 1 Flowchart of patients and controls. DAS28, 28-Joint Disease Activity Score; DM, diabetes mellitus; OGTT, oral glucose tolerance test; RA, rheumatoid arthritis.

\section{RESULTS}

The initial study population comprised 100 patients and 100 controls. However, only 89 patients with RA and 80 healthy controls fulfilled the inclusion criteria and none of the exclusion criteria. The study flowchart is shown in figure 1 .

\section{Epidemiological and anthropometric characteristics and comorbidities}

Table 1 shows the baseline characteristics of patients and controls. The mean age was slightly over 56 years, and most patients were women (75\%). Patients with RA more frequently had a family history of cardiovascular disease than controls, and $10 \%$ more were ex-smokers.

\section{Clinical and analytical variables associated with RA}

Autoantibodies were only detected in patients, except for one participant in the control group, who was positive for rheumatoid factor, with a low titre and no other data indicating inflammatory disease. On the index date, most patients were in remission or had low arthritis-related inflammatory activity and had maintained an average DAS28-CRP score of $<3.2$ throughout follow-up (table 1 ). All patients had received DMARDs. A total of $78 / 89$ patients with RA (87.6\%) were using synthetic DMARDs; 35/89 (39.3\%) were using biologic DMARDs; and 12/89 $(13.5 \%)$ were using corticosteroids.

While the rate of adherence to a Mediterranean diet was similar in both groups $(62.9 \%$ vs $57.5 \%, \mathrm{p}=0.472)$, healthy participants more often engaged in physical activity than patients (median 612.0, IQR 313.5-1089.0 METS, vs median 339.0, IQR 198.0-792.0 METS; $\mathrm{p}=0.005$ ).

Both patients and controls generally had similar baseline characteristics with respect to carbohydrate metabolism (ie, resistance and sensitivity to insulin, glycaemia and baseline insulinaemia). While patients had slightly higher blood sugar levels after OGTT, the difference was not clinically relevant. As for lipids, patients with RA had slightly lower levels of total cholesterol and LDL cholesterol than controls (table 2). 
Table 1 Baseline characteristics of cases and controls

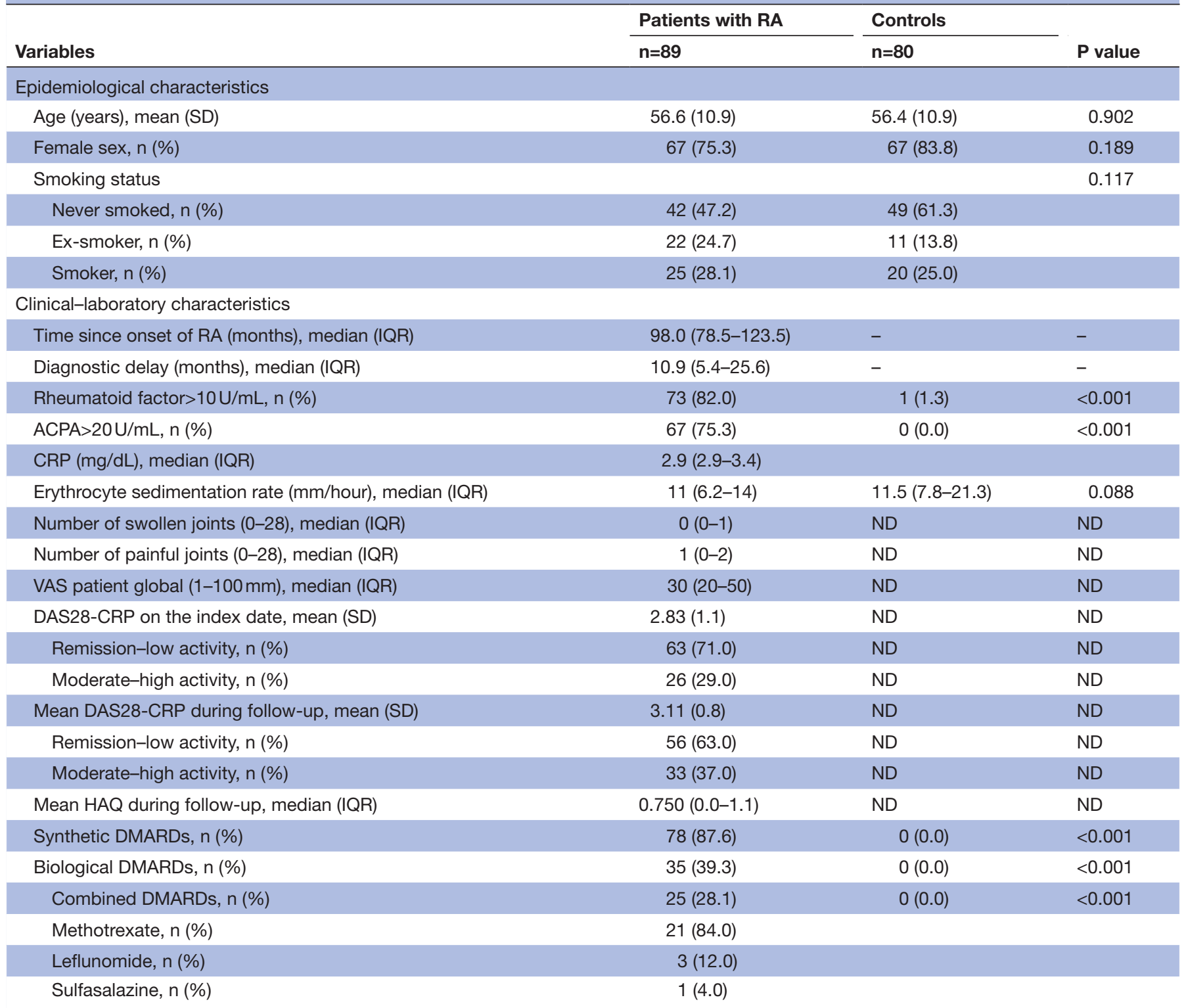

ACPA, anticitrullinated protein antibody; CRP, C reactive protein; DAS28, 28-Joint Disease Activity Score; DMARD, disease-modifying antirheumatic drug; HAQ, Health Assessment Questionnaire; ND, no data; RA, rheumatoid arthritis; VAS, visual analogue scale.

\section{Inflammatory cytokines and adipokines}

Disease was controlled in most patients with RA. However, patients with RA had higher levels of proinflammatory cytokines (ie, TNF- $\alpha$, IL-6 and IL-1 $\beta$ ) than controls. Similarly, IGF-1 levels tended to be higher in patients. The only adipokine that was elevated in patients was adiponectin. Resistin and leptin remained similar in both groups (table 2).

\section{Characteristics of patients with RA and IR}

Of the 89 patients with RA, 25 (28.1\%) had a HOMA-IR of $\geq 2.29$. Table 3 shows the characteristics of patients with RA with and without IR. As we can see, the epidemiological characteristics of patients with IR were similar to those of the others, although clinical control of their disease was worse on the index date (DAS28-CRP score $>3.2$,
$68 \%$ vs $28 \% ; \mathrm{p}=0.001$ ) and throughout follow-up (mean DAS28-CRP score $3.5(0.7)$ vs $2.9(0.7), p=0.001)$. It is also important to note that patients with IR had higher values for BMI, weight and body composition, and were more often obese. They also had a higher percentage of fat and a higher Waist-Hip Index. However, no differences were found between the groups with respect to the delay in diagnosis of RA, duration of symptoms, antibodies and synthetic and biological DMARDs or corticosteroids (table 3).

There was no association between Mediterranean diet in patients with and without IR $(52.9 \%$ vs $65.3 \%$, $\mathrm{p}=0.472$ ). Likewise, physical activity was similar in both groups (median 445.5, IQR 165.0-800.0 METS, vs median 330.0, IQR 198.0-700.0 METS; $\mathrm{p}=0.834$ ). 
Table 2 Anthropometric and metabolic characteristics, inflammatory cytokines and adipokines

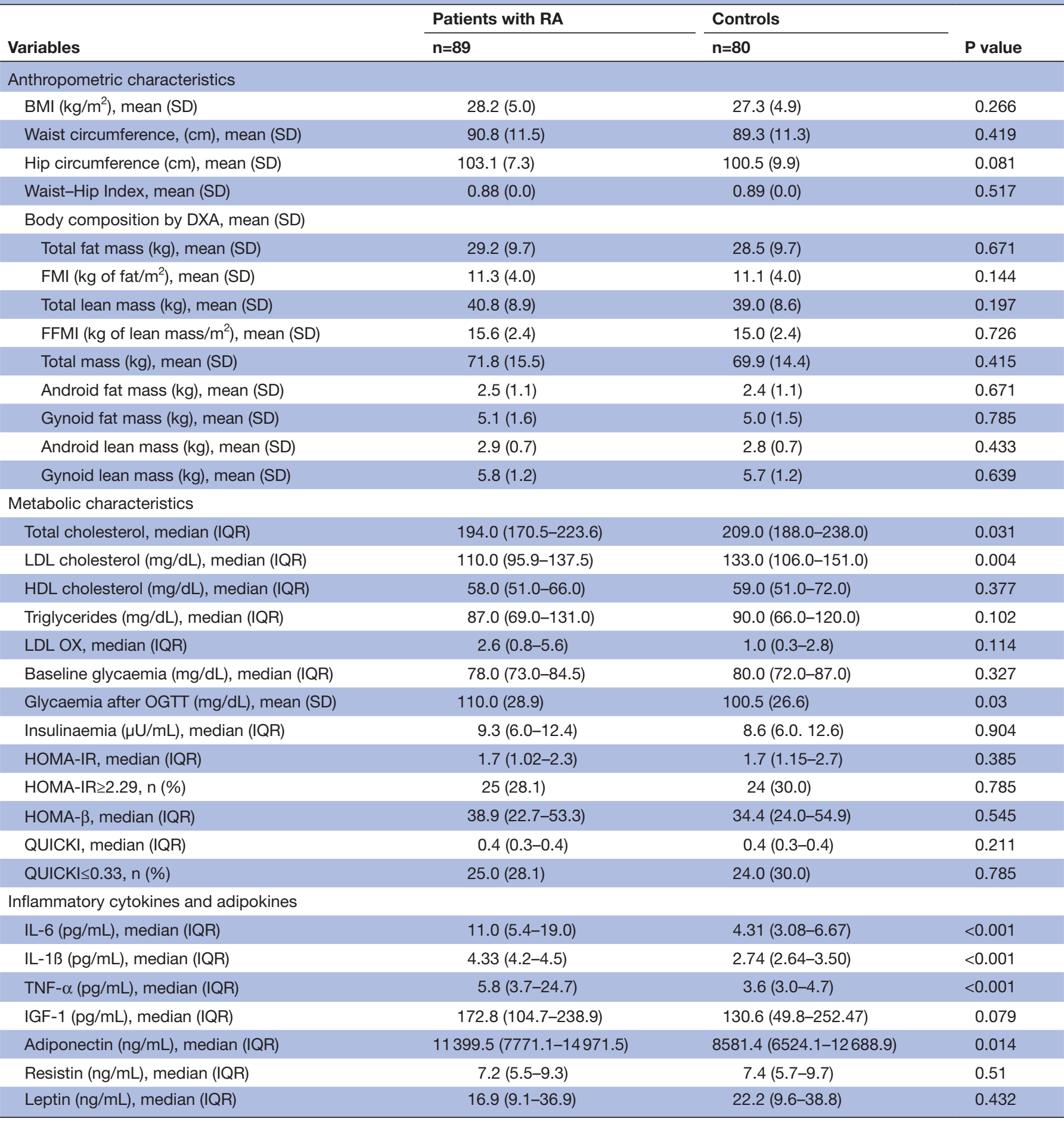

BMI, Body Mass Index; DXA, dual-energy X-ray absorptiometry; FFMI, Fat-Free Mass Index; FMI, Fat Mass Index; HDL, high-density lipoprotein; HOMA- $\beta$, homeostasis model assessment for $\beta$-cell function; HOMA-IR, homeostasis model assessment for insulin resistance; IGF-1, insulin-like growth factor-1; IL, interleukin; LDL, low-density lipoprotein; LDL-OX, oxidised low-density lipoprotein; OGTT, oral glucose tolerance test; QUICKI, Quantitative Insulin Sensitivity Check Index; RA, rheumatoid arthritis; TNF- $\alpha$, tumour necrosis factor alpha.

With respect to inflammatory cytokines and adipokines, concentrations of IL-1 $\beta$ and leptin were clearly higher in patients with IR. No differences were found between the groups in concentrations of TNF- $\alpha$ and IL- 6 or in levels of resistin and adiponectin.

\section{Factors associated with insulin resistance (IR) in RA}

Table 4 shows the two best multivariate models. In the first, obesity, mean DAS28 and IL-1ß were significantly associated with IR; these factors accounted for $35 \%$ of variability in the presence of IR $\left(R^{2}=0.352\right)$. In the second 
Table 3 Characteristics of patients with and without IR measured using HOMA-IR

\begin{tabular}{|c|c|c|c|}
\hline \multirow[b]{3}{*}{ Variables } & RA & RA & \multirow[b]{3}{*}{$P$ value } \\
\hline & HOMA-IR $\geq 2.29$ & HOMA-IR<2.29 & \\
\hline & $\mathrm{n}=\mathbf{2 5}$ & $n=64$ & \\
\hline Female sex, $\mathrm{n}(\%)$ & $17(68.0)$ & $50(78.1)$ & 0.32 \\
\hline \multicolumn{4}{|l|}{ Clinical characteristics } \\
\hline Time since onset of RA (months), median (IQR) & $95.8(81.8-111.6)$ & $98.1(77.5-125.5)$ & 0.697 \\
\hline Arterial hypertension, n (\%) & $7(28.0)$ & $16(25.0)$ & 0.771 \\
\hline Dyslipidaemia, n (\%) & $8(32.0)$ & $13(20.3)$ & 0.243 \\
\hline Rheumatoid factor, n (\%) & $20(80.0)$ & $53(82.8)$ & 0.756 \\
\hline ACPA, n (\%) & $17(68.0)$ & $49(76.0)$ & 0.407 \\
\hline DAS28-CRP>3.2 on the index date, $n(\%)$ & $17(68.0)$ & $18(28.1)$ & 0.001 \\
\hline Biological DMARD, n (\%) & $10(40.0)$ & $19(29.7)$ & 0.351 \\
\hline Combined DMARD, n (\%) & $7(28.0)$ & $18(28.1)$ & 0.991 \\
\hline \multicolumn{4}{|l|}{ Anthropometric characteristics } \\
\hline Weight, mean (SD) & $82.6(13.1)$ & $69.5(12.5)$ & $<0.001$ \\
\hline BMI, mean (SD) & $31.9(5.4)$ & $26.8(4.0)$ & $<0.001$ \\
\hline Normal weight, $\mathrm{n}(\%)$ & $1(4.0)$ & $27(42.2)$ & \\
\hline Overweight, n (\%) & $9(36.0)$ & $22(34.4)$ & \\
\hline Obesity, n (\%) & $15(60.0)$ & $15(23.4)$ & \\
\hline Waist circumference, mean (SD) & $97.5(8.9)$ & $88.1(11.4)$ & 0.001 \\
\hline FFMI (kg of lean mass $/ \mathrm{m}^{2}$ ), mean (SD) & $16.8(2.4)$ & $15.1(2.2)$ & 0.006 \\
\hline Lean mass percentage, mean (SD) & $0.53(0.1)$ & $0.58(0.1)$ & 0.051 \\
\hline Total mass (kg), mean (SD) & $81.9(12.6)$ & $67.9(14.7)$ & $<0.001$ \\
\hline Android fat mass (kg), mean (SD) & $34.6(0.7)$ & $22.3(9.1)$ & $<0.001$ \\
\hline Gynoid fat mass (kg), mean (SD) & $59.5(1.0)$ & $47.9(1.3)$ & 0.003 \\
\hline Android lean mass (kg), mean (SD) & $32.0(0.5)$ & $28.2(0.7)$ & 0.014 \\
\hline Gynoid lean mass (kg), mean (SD) & $64.0(1.0)$ & $55.0(1.2)$ & 0.003 \\
\hline LDL OX, median (IQR) & $2.7(0.7-7.4)$ & $2.5(0.7-5.5)$ & 0.868 \\
\hline \multicolumn{4}{|l|}{ Inflammatory cytokines and adipokines } \\
\hline IL-6 (pg/mL), median (IQR) & $11.1(7.3-20.8)$ & $10.5(4.9-19.8)$ & 0.495 \\
\hline IL-1 $\beta$ (pg/mL), median (IQR) & $4.9(4.1-4.4)$ & $4.3(4.0-4.5)$ & 0.007 \\
\hline TNF- $\alpha$ (pg/mL), median (IQR) & $5.1(3.3-27.0)$ & $5.8(3.7-23.5)$ & 0.827 \\
\hline IGF-1 (pg/mL), mean (SD) & $168.5(93.8)$ & $187.7(106.6)$ & 0.433 \\
\hline Adiponectin (ng/mL), median (IQR) & $9271.8(7602.0-12407.0)$ & $12273.1(8218.5-15677.1)$ & 0.21 \\
\hline Resistin (ng/mL), median (IQR) & $8.3(5.6-9.9)$ & $7.1(5.5 .-9.0)$ & 0.626 \\
\hline Leptin (ng/mL), median (IQR) & $33.7(18.0-55.2)$ & $13.9(7.9-26.1)$ & 0.001 \\
\hline
\end{tabular}

ACPA, anticitrullinated protein antibody; BMI, Body Mass Index; CRP, C reactive protein; DAS28, 28-Joint Disease Activity Score; DMARD, disease-modifying antirheumatic drug; DXA, dual-energy X-ray absorptiometry; FFMI, Fat-Free Mass Index; FMI, Fat Mass Index; HAQ, Health Assessment Questionnaire; HDL, highdensity lipoprotein; HOMA-IR, homeostatic model assessment for insulin resistance; IGF-1, insulin-like growth factor-1; IL, interleukin; IR, insulin resistance; LDL, low-density lipoprotein; LDL-OX, oxidised low-density lipoprotein; ND, no data; RA, rheumatoid arthritis; TNF- $\alpha$, tumour necrosis factor alpha. 
Table 4 Multivariate models for patients with RA with HOMA-IR >2.29 (dependent variable)

\begin{tabular}{lllll}
\hline Predictor & $\boldsymbol{\beta}$ & OR & $\mathbf{9 5 \%} \mathbf{C l}$ & P value \\
\hline Multivariate model 1 & using obesity covariate & \\
\hline Obesity (BMl>30) & 1.795 & 6.01 & 1.94 to 8.66 & 0.002 \\
Mean DAS28-CRP & 1.021 & 2.77 & 1.29 to 5.99 & 0.009 \\
$\mathrm{IL}-1 \beta(\mathrm{pg} / \mathrm{mL})$ & 0.464 & 1.59 & 1.06 to 2.38 & 0.024 \\
$\mathrm{R}^{2}=0.352$ & & & & \\
\hline
\end{tabular}

Independent variables: age, sex, obesity (BMI>30), mean

DAS28-CRP score, diagnostic delay, sedentary lifestyle

\begin{tabular}{llllll} 
Multivariate model 2 using total fat mass covariate \\
\hline Total fat mass $(\mathrm{kg})$ & 0.123 & 1.1 & 1.05 to 1.22 & 0.002 \\
Mean DAS28-CRP & 0.955 & 2.6 & 1.19 to 5.69 & 0.017 \\
$\mathrm{IL}-1 \beta(\mathrm{pg} / \mathrm{mL})$ & 0.456 & 1.57 & 1.06 to 2.34 & 0.023 \\
$\mathrm{R}^{2}=0.404$ & & & &
\end{tabular}

Independent variables: age, sex, fat mass, lean mass, mean

DAS28, diagnostic delay, sedentary lifestyle

BMI, Body Mass Index; CRP, C reactive protein; DAS28, 28-Joint Disease Activity Score; HOMA-IR, homeostasis model assessment for insulin resistance; IL, interleukin; RA, rheumatoid arthritis.

model, fat mass, mean DAS28 and IL-1ß were associated with IR; these factors accounted for $40 \%$ of the variability in IR $\left(R^{2}=0.404\right)$.

\section{DISCUSSION}

Among patients with RA, there is a high prevalence of comorbidities and cardiovascular risk factors, as shown in the International COMORA (COMOrbidities in Rheumatoid Arthritis) study. ${ }^{35}$ Given that RA is currently considered as potent a cardiovascular risk factor as type $2 \mathrm{DM}$, some risk equations take it into account. ${ }^{36}$ Although cardiovascular risk may be mediated in part by $\mathrm{IR},{ }^{9}{ }^{17-25}$ our study did not reveal a higher prevalence of IR in patients with RA because the disease was well controlled in patients with a cumulative mean DAS28 score of $<3.2$ from onset. This finding is consistent with data from other authors who observed a reduction in IR associated with control of the inflammatory activity induced by methotrexate and anti-TNF- $\alpha$ agents. ${ }^{37}$ However, these results contrast with those published elsewhere, owing to methodological differences, especially in the measurement of inflammation and matching of controls. ${ }^{5}{ }^{14}$ Our study, in contrast, was based on inflammation data obtained from patients with established RA followed prospectively since onset. We also included controls matched for age, sex, race and BMI, and the amount of exercise and adherence to the Mediterranean diet were taken into account.

While no differences were found between cases and controls, our results support an association between IR and chronic inflammation, as confirmed elsewhere. ${ }^{14} 1637-40$ Our group studied baseline IR in patients with untreated early-onset RA and found an association between IR and time with untreated symptoms and fat mass percentage. ${ }^{16}$ Both of these aspects are important for tight and early control of arthritis. In fact, when we analyse the determinants of IR in patients with RA, we again find a higher risk in patients with poor control of their disease during its course, higher levels of IL-1 $\beta$, and more pronounced obesity. While the cytokines TNF- $\alpha$, IL-6 and IL- $1 \beta$ are abundant in patients with active RA and reflect inflammatory status and their involvement in IR has been suggested, ${ }^{41}$ the first two may not play as important a role in the present study because the vast majority of patients treated with biologics received antiTNF- $\alpha$ agents or tocilizumab. However, in addition to treatment, other aspects associated with IL-1 $\beta$ may have an effect. Although the role of IL-1 $\beta$ has recently been questioned, ${ }^{42}$ it has been thought to play a role in the pathogenesis of type $2 \mathrm{DM}^{43}$ These authors indicate that high blood sugar levels could induce more marked production of IL-1 $\beta$ and TNF- $\alpha$ in macrophages and that this, in turn, could lead to a greater rate of apoptosis of $\beta$ cells that would eventually lead to impairment of pancreatic function. ${ }^{43}$ In this sense, some studies report greater production of IL-1 $\beta$ in patients affected by RA and type $2 \mathrm{DM}$ as a result of activation of the NLRP3 inflammasome, thus suggesting a role for therapy targeting IL-1 $\beta$ in these patients. ${ }^{44}$ Furthermore, there have been reports of cases of patients with diabetes with RA whose arthritis has remitted and whose metabolism has been controlled with IL-1 $\beta$ blockers. ${ }^{46}$ In addition, in this context, Ruscitti et $a l^{47}$ recently performed a specifically designed clinical trial to investigate inhibition of IL-1 as 'bidirectional' therapy in patients with RA and type $2 \mathrm{DM}$. The authors observed an apparent benefit of this approach in participants with RA and type 2DM. The fact that the therapeutic targets were reached in both diseases suggests that inhibition of IL-1 may be considered a therapeutic target for RA and type $2 \mathrm{DM}$.

On the other hand, while we found no differences between patients with RA with or without IR regarding the use of DMARDs (synthetic and biological), some authors observed that the probabilities of using bDMARDs decrease by $11 \%$ for each additional chronic morbid condition, ${ }^{48}$ possibly as a result of the higher number of chronic conditions in these patients than in our cohort.

Our results showed that patients and controls did not differ overall in BMI or in body composition. While this observation can be explained in part by matching for BMI, disease control with biological DMARDs is associated with recovery of total appendicular lean mass, with no changes in fat distribution. ${ }^{49}$ Nevertheless, despite treat-to-target strategies, as applied in our study, patients with RA experience a relative loss of muscle mass and an increase in adiposity, ${ }^{50}$ which we found to be more evident in those with poorer control of inflammation and more pronounced IR. Obesity is more frequent in patients with RA and is closely associated with IR, ${ }^{51}{ }^{52}$ probably owing to physical inactivity, sarcopenia and therapy with corticosteroids. Obese patients with RA in the present study 
had a sixfold greater risk of IR than the other patients; this probability was mediated mainly by fat mass since the risk increased by $10 \%$ for each kilogram of excess body fat. These data support those found in other studies, which highlight the fact that inflammation and obesity are closely linked, because adipose tissue produces TNF- $\alpha$ and IL-6. ${ }^{1652}$

In addition to proinflammatory cytokines, adipokines produced by fatty tissue may affect glucose homeostasis, appetite and the inflammatory response. ${ }^{53}$ We found that adiponectin levels were higher in patients than in controls. While results were sometimes contradictory, it seems that adiponectin could increase in patients with RA as a means of offsetting the proinflammatory effects of high levels of leptin or of TNF- $\alpha$ and IL- $6 .{ }^{53}$ This increase may also be a result of the effect of treatment with DMARDs. ${ }^{54}$

Leptin levels (systemic, local or both) have been reported to increase in various inflammatory diseases. ${ }^{53}$ However, we observed an increase only in patients with RA and IR. Consistent with some studies, this could be because these patients had a greater BMI and a higher grade of chronic inflammation. ${ }^{55}$

Furthermore, our data show an increase in LDL oxidase and a decrease in IGF-1 that tended towards significance in patients with RA compared with healthy controls. The same finding was observed in other studies in which these parameters were associated with increased cardiovascular risk in RA. ${ }^{5657}$

Our study is limited mainly by the cross-sectional evaluation of IR between patients with RA and healthy participants. However, these patients came from a prospective RA inception cohort in which we longitudinally collected all inflammation-related variables analysed using a predesigned protocol. Consequently, no data were missing, and our results are consistent. On the other hand, while the use of HOMA-IR instead of the hyperinsulinaemiceuglycaemic clamp method may seem to be a limitation, indirect methods such as HOMA and QUICKI have been validated for use. They are reliable indices and can replace the clamp method for measuring IR in epidemiological studies, clinical trials and clinical practice. Among the strengths of this study, we performed OGTT, the only technique that makes it possible to recognise the presence of impaired glucose tolerance. Another strength is that the control group was matched with the cases not only for age and sex but also for BMI.

In conclusion, our results show that the main factors associated with IR are obesity, specifically total fat mass and disease activity, specifically levels of IL-1 $\beta$ and cumulative inflammatory burden, measured based on average DAS28-CRP levels throughout follow-up. Therefore, early treatment and good control of inflammatory activity and weight are essential for reducing the risk of IR and accelerated atherosclerosis. However, controlled prospective studies must continue to be performed in order to better observe the possible causal relationship between clinical and metabolic factors and IR and atherosclerosis in RA.

\section{Author affiliations}

${ }^{1}$ UGC de Reumatología, Instituto de Investigación Biomédica de Málaga (IBIMA), Hospital Regional Universitario de Málaga, Málaga, Spain

${ }^{2}$ Departamento de Medicina y Dermatología, Instituto de Investigación Biomédica de Málaga (IBIMA), Universidad de Málaga, Málaga, Spain

${ }^{3}$ UGC de Medicina Interna, Instituto de InvestigaciónBiomédica de Málaga (IBIMA), Hospital Universitario Virgen de la Victoria, Universidad de Málaga, Málaga, Spain ${ }^{4}$ Centro de Salud Ciudad Jardín, Distrito Sanitario Málaga-Guadalhorce, Málaga, Spain

${ }^{5}$ UGC Neurociencias, Instituto de Investigación Biomédica de Málaga (IBIMA), Hospital Regional Universitario de Málaga, Málaga, Spain

Acknowledgements To the Spanish Rheumatology Society (SER) for the translation of the manuscript and to the patients for their participation in the study.

Contributors SM-A contributed including patients, writing the manuscript and contributed analysing and interpreting the patient data. NM-V contributed writing the manuscript, and analysing and interpreting the patient data. IU was a major contributor in including patients. JR was a major contributor in performing laboratory determination, and contributed interpreting laboratory data. PV contributed was a contributor in interpreting the patient data and writing the manuscript. LG-M was a major contributor in including controls. SA-S was a major contributor in including controls. FGJ-N contributed including patients. BO-M contributed performing laboratory determination and interpreting laboratory data. AF-N contributed writing the manuscript, and analysing and interpreting the patient data. All authors read and approved the final manuscript.

Funding Grant from the Spanish Foundation of Rheumatology 2015 in the non-funded projects modality. Grant for Medical Researchers from the Spanish Foundation of Rheumatology 2019.

Competing interests None declared.

Patient consent for publication Obtained.

Ethics approval The study was approved by the ethics committee of HRUM. All participants signed an informed consent document.

Provenance and peer review Not commissioned; externally peer reviewed.

Data availability statement No additional data available.

Supplemental material This content has been supplied by the author(s). It has not been vetted by BMJ Publishing Group Limited (BMJ) and may not have been peer-reviewed. Any opinions or recommendations discussed are solely those of the author(s) and are not endorsed by BMJ. BMJ disclaims all liability and responsibility arising from any reliance placed on the content. Where the content includes any translated material, BMJ does not warrant the accuracy and reliability of the translations (including but not limited to local regulations, clinical guidelines, terminology, drug names and drug dosages), and is not responsible for any error and/or omissions arising from translation and adaptation or otherwise.

Open access This is an open access article distributed in accordance with the Creative Commons Attribution Non Commercial (CC BY-NC 4.0) license, which permits others to distribute, remix, adapt, build upon this work non-commercially, and license their derivative works on different terms, provided the original work is properly cited, appropriate credit is given, any changes made indicated, and the use is non-commercial. See: http://creativecommons.org/licenses/by-nc/4.0/.

\section{ORCID iDs}

Natalia Mena-Vazquez http://orcid.org/0000-0001-6173-2051

Antonio Fernandez-Nebro http://orcid.org/0000-0002-2962-9844

\section{REFERENCES}

1 Goodson N, Marks J, Lunt M, et al. Cardiovascular admissions and mortality in an inception cohort of patients with rheumatoid arthritis with onset in the 1980s and 1990s. Ann Rheum Dis 2005;64:1595-601.

2 Espiño-Lorenzo P, Manrique-Arija S, Ureña I, et al. Baseline comorbidities in patients with rheumatoid arthritis who have been prescribed biological therapy: a case control study. Reumatol Clin 2013;9:18-23.

3 Peters MJL, van Halm VP, Voskuyl AE, et al. Does rheumatoid arthritis equal diabetes mellitus as an independent risk factor for cardiovascular disease? A prospective study. Arthritis Rheum 2009;61:1571-9. 
4 Sattar N, McCarey DW, Capell H, et al. Explaining how "high-grade" systemic inflammation accelerates vascular risk in rheumatoid arthritis. Circulation 2003;108:2957-63.

5 La Montagna G, Cacciapuoti F, Buono R, et al. Insulin resistance is an independent risk factor for atherosclerosis in rheumatoid arthritis. Diab Vasc Dis Res 2007;4:130-5.

6 Grundy SM. What is the contribution of obesity to the metabolic syndrome? Endocrinol Metab Clin North Am 2004;33:267-82.

7 Park K, Steffes M, Lee D-H, et al. Association of inflammation with worsening HOMA-insulin resistance. Diabetologia 2009;52:2337-44.

8 Meng Y-X, Ford ES, Li C, et al. Association of C-reactive protein with surrogate measures of insulin resistance among nondiabetic us from national health and nutrition examination survey 1999-2002. Clin Chem 2007:53:2152-9.

9 Li G, Barrett EJ, Barrett MO, et al. Tumor necrosis factor-alpha induces insulin resistance in endothelial cells via a p38 mitogenactivated protein kinase-dependent pathway. Endocrinology 2007;148:3356-63.

10 El-Hini SH, Mohamed FI, Hassan AA, et al. Visfatin and adiponectin as novel markers for evaluation of metabolic disturbance in recently diagnosed rheumatoid arthritis patients. Rheumatol Int 2013;33:2283-9.

11 Matthews DR, Hosker JP, Rudenski AS, et al. Homeostasis model assessment: insulin resistance and beta-cell function from fasting plasma glucose and insulin concentrations in man. Diabetologia 1985;28:412-9.

12 Dessein PH, Stanwix AE, Joffe BI. Cardiovascular risk in rheumatoid arthritis versus osteoarthritis: acute phase response related decreased insulin sensitivity and high-density lipoprotein cholesterol as well as clustering of metabolic syndrome features in rheumatoid arthritis. Arthritis Res 2002;4:R5.

13 Rosenvinge A, Krogh-Madsen R, Baslund B, et al. Insulin resistance in patients with rheumatoid arthritis: effect of anti-TNFalpha therapy. Scand J Rheumatol 2007;36:91-6.

14 Shahin D, Eltoraby E, Mesbah A, et al. Insulin resistance in early untreated rheumatoid arthritis patients. Clin Biochem 2010;43:661-5

15 Castañeda S, Martín-Martínez MA, González-Juanatey C, et al. Cardiovascular morbidity and associated risk factors in Spanish patients with chronic inflammatory rheumatic diseases attending rheumatology clinics: baseline data of the CARMA project. Semin Arthritis Rheum 2015;44:618-26.

16 Manrique-Arija S, Ureña I, Valdivielso P, et al. Insulin resistance and levels of adipokines in patients with untreated early rheumatoid arthritis. Clin Rheumatol 2016;35:43-53.

17 Aletaha D, Neogi T, Silman AJ, et al. 2010 rheumatoid arthritis classification criteria: an American College of Rheumatology/ European League against rheumatism collaborative initiative. Arthritis Rheum 2010;62:2569-81.

18 American Diabetes Association. Consensus development conference on insulin resistance. 5-6 November 1997. American diabetes association. Diabetes Care 1998;21:310-4.

19 Sociedad Española de Reumatología. GUIPCAR actualización 2011: Actualizaciónde la guía de práctica clínica para el manejo de la artritis reumatoide en ESPAÑA (updated [30 diaciembre 2011) [online]. Madrid: Sociedad Española de Reumatología, 2007.

20 Rojo-Martínez G, Esteva I, de Adana SR, et al. Patterns of insulin resistance in the general population of Southeast Spain. Diabetes Res Clin Pract 2004;65:247-56.

21 Katz A, Nambi SS, Mather K, et al. Quantitative insulin sensitivity check index: a simple, accurate method for assessing insulin sensitivity in humans. J Clin Endocrinol Metab 2000;85:2402-10.

22 Mancia G, De Backer G, Dominiczak A, et al. ESH/ESC 2007 Guidelines for the management of arterial hypertension. Rev Esp Cardiol 2007:60:68e1-94.

23 American Diabetes Association. Diagnosis and classification of diabetes mellitus. Diabetes Care 2010;33:S62-9.

24 Expert Panel on Detection, Evaluation, and Treatment of High Blood Cholesterol in Adults. Executive summary of the third report of the National cholesterol education program (NCEP) expert panel on detection, evaluation, and treatment of high blood cholesterol in adults (adult treatment panel III). JAMA 2001;285:2486-97.

25 Friedewald WT, Levy RI, Fredrickson DS. Estimation of the concentration of low-density lipoprotein cholesterol in plasma, without use of the preparative ultracentrifuge. Clin Chem 1972;18:499-502.

26 Guidelines for data processing andAnalysis of the International physical activity questionnaire (IPAQ) 2009.

27 Craig CL, Marshall AL, Sjöström M, et al. International physical activity questionnaire: 12 -country reliability and validity. Med Sci Sports Exerc 2003;35:1381-95.
28 Estruch R, Ros E, Salas-Salvadó J, et al. Primary prevention of cardiovascular disease with a Mediterranean diet. N Engl J Med 2013;368:1279-90.

29 WHO. Obesity preventing and managing the global epidemic. Geneva: WHO, 1997

30 Anonymous World Health Organization Expert Committee. Physical status: the use and interpretation of anthropometry. WHO; Genova: technical report series 1995

31 Taylor AE, Kuper H, Varma RD, et al. Validation of dual energy X-ray absorptiometry measures of abdominal fat by comparison with magnetic resonance imaging in an Indian population. PLOS One 2012; 7:e51042.

32 Iwamoto N, Kawakami A, Fujikawa K, et al. Prediction of DAS28ESR remission at 6 months by baseline variables in patients with rheumatoid arthritis treated with etanercept in Japanese population. Mod Rheumatol 2009;19:488-92.

33 Moyano S, Scolnik M, Vergara F, et al. Evaluation of learned helplessness, perceived self-efficacy, and functional capacity in patients with fibromyalgia and rheumatoid arthritis. J Clin Rheumatol 2018.

34 Chung CP, Oeser A, Solus JF, et al. Prevalence of the metabolic syndrome is increased in rheumatoid arthritis and is associated with coronary atherosclerosis. Atherosclerosis 2008;196:756-63.

35 Dougados M, Soubrier M, Antunez A, et al. Prevalence of comorbidities in rheumatoid arthritis and evaluation of their monitoring: results of an international, cross-sectional study (COMORA). Ann Rheum Dis 2014;73:62-8.

36 Hippisley-Cox J, Coupland C, Brindle P. Development and validation of QRISK3 risk prediction algorithms to estimate future risk of cardiovascular disease: prospective cohort study. BMJ 2017;357:j2099.

37 Gonzalez-Gay MA, De Matias JM, Gonzalez-Juanatey C, et al. Antitumor necrosis factor-alpha blockade improves insulin resistance in patients with rheumatoid arthritis. Clin Exp Rheumatol 2006;24:83-6.

38 Pannacciulli N, Cantatore FP, Minenna A, et al. C-reactive protein is independently associated with total body fat, central fat, and insulin resistance in adult women. Int J Obes Relat Metab Disord 2001;25:1416-20.

39 Crepaldi G, Scirè CA, Carrara G, et al. Cardiovascular comorbidities relate more than others with disease activity in rheumatoid arthritis. PLoS One 2016;11:e0146991.

40 Ruscitti P, Ursini F, Cipriani P, et al. Poor clinical response in rheumatoid arthritis is the main risk factor for diabetes development in the short-term: a 1-year, single-centre, longitudinal study. PLoS One 2017;12:e0181203.

41 Fève B, Bastard J-P. The role of interleukins in insulin resistance and type 2 diabetes mellitus. Nat Rev Endocrinol 2009;5:305-11.

42 Everett BM, Donath MY, Pradhan AD, et al. Anti-Inflammatory therapy with canakinumab for the prevention and management of diabetes. $J$ Am Coll Cardiol 2018;71:2392-401.

43 Donath MY, Shoelson SE. Type 2 diabetes as an inflammatory disease. Nat Rev Immunol 2011;11:98-107.

44 Fève $B$, Bastard J-P. The role of interleukins in insulin resistance and type 2 diabetes mellitus. Nat Rev Endocrinol 2009;5:305-11.

45 Ruscitti P, Cipriani P, Di Benedetto P, et al. Monocytes from patients with rheumatoid arthritis and type 2 diabetes mellitus display an increased production of interleukin (IL)-1 $\beta$ via the nucleotide-binding domain and leucine-rich repeat containing family pyrin 3(NLRP3)inflammasome activation: a pos. Clin Exp Immunol 2015;182:35-44.

46 Ruscitti P, Cipriani P, Cantarini L, et al. Efficacy of inhibition of IL-1 in patients with rheumatoid arthritis and type 2 diabetes mellitus: two case reports and review of the literature. J Med Case Rep 2015;9:123.

47 Ruscitti P, Masedu F, Alvaro S, et al. Anti-Interleukin-1 treatment in patients with rheumatoid arthritis and type 2 diabetes (track): a multicentre, open-label, randomised controlled trial. PLoS Med 2019;16:e1002901.

48 Radner H, Yoshida K, Hmamouchi I, et al. Treatment patterns of Multimorbid patients with rheumatoid arthritis: results from an international cross-sectional study. J Rheumatol 2015;42:1099-104.

49 Tournadre A, Pereira B, Dutheil F, et al. Changes in body composition and metabolic profile during interleukin 6 inhibition in rheumatoid arthritis. J Cachexia Sarcopenia Muscle 2017;8:639-46.

50 Lemmey AB, Wilkinson TJ, Clayton RJ, et al. Tight control of disease activity fails to improve body composition or physical function in rheumatoid arthritis patients. Rheumatology 2016;55:1736-45.

51 Müller R, Kull M, Lember M, et al. Insulin resistance in early rheumatoid arthritis is associated with low appendicular lean mass. Biomed Res Int 2017;2017:9584720

52 Castillo-Hernandez J, Maldonado-Cervantes MI, Reyes JP, et al. Obesity is the main determinant of insulin resistance more than the 
circulating pro-inflammatory cytokines levels in rheumatoid arthritis patients. Revista Brasileira de Reumatologia 2017;57:320-9.

53 Otero M, Lago R, Gomez R, et al. Changes in plasma levels of fat-derived hormones adiponectin, leptin, resistin and visfatin in patients with rheumatoid arthritis. Ann Rheum Dis 2006;65:1198-201.

54 Cansu B, Cansu DU, Kașifoğlu T, et al. Disease-modifying antirheumatic drugs increase serum adiponectin levels in patients with rheumatoid arthritis. J Clin Rheumatol 2011;17:14-17.
55 Popa C, Netea MG, Radstake TR. Markers of inflammation are negatively correlated with serum leptin in rheumatoid arthritis. Ann Rheum Dis 2005;64:1195-8.

56 Erlandsson MC, Lyngfelt L, Åberg ND, et al. Low serum IGF1 is associated with hypertension and predicts early cardiovascular events in women with rheumatoid arthritis. BMC Med 2019;17:141.

57 Nowak B, Madej M, Łuczak A, et al. Disease activity, Oxidized-LDL fraction and anti-oxidized LDL antibodies influence cardiovascular risk in rheumatoid arthritis. Adv Clin Exp Med 2016;25:43-50. 